$339.92(510)(497)(497.11)$

https://doi.org/10.18485/fb_nps.2018.ch10

\title{
Žarko Obradović
}

Vanredni profesor, Univerzitet u Beogradu - Fakultet bezbednosti

\section{„POJAS I PUT" NA BALKANU \\ I SRBIJI \\ (izazovi saradnje)}

\begin{abstract}
Sažetak
Kineska Inicijativa „Pojas i put” o povezivanju prostora Kine (Azija) sa Afrikom i Evropom brojnim putnim i železničkim pravcima i saradnji država u različitim oblastima obuhvata u svom zapadnom delu na prostoru Evrope i sve države na Balkanu. Sve one sarađuju sa NR Kinom, bilateralno i unutar procesa saradnje Kine sa zemljama Centralne i Istočne Evrope. Neke od balkanskih država su članice Evropske unije, dok su ostale kandidati za članstvo, ali za sve je zajedničko da nastoje da unaprede svoje odnose sa Kinom kroz realizaciju različitih projekata. Uzimajući u obzir nameru Evropske unije da „prati” poslovanje kineskih kompanija u zemljama članicama i realizaciju infrastrukturnih i drugih projekata saradnje balkanskih država sa NR Kinom, sudbina te saradnje i projekata zavisiće nesumnjivo od odnosa (i interesa) EU prema Kini. Mogućnost uticaja Evropske unije biće veća prema svojim članicama u odnosu na države kandidate za članstvo. Takav odnos, sa druge strane, daje zemljama kandidatima veće mogućnosti za saradnju sa Kinom, pogotovo Srbiji, koja među svim državama na Balkanu ima najviši nivo međudržavnih odnosa sa NR Kinom, najveći broj započetih i (do sada) završenih projekata. Mogućnosti uticaja drugih velikih država na realizaciju Inicijative "Pojas i put” na prostoru Balkana su bitno umanjene ili ne postoje, bilo zbog toga što te zemlje ne smatraju NR Kinu geopolitičkim suparnikom na ovim prostorima (SAD npr.) ili zbog toga što imaju dobre bilateralne odnose sa Kinom i aktivno učestvuju u realizaciji „Pojasa i puta”, kao što je reč o Turskoj.
\end{abstract}

Ključne reči:

Pojas i put, balkanske države, Kina, Evropska unija, velike sile, izazovi saradnje 
Inicijativa „Pojas i put”, o povezivanju prostora Azije sa Afrikom i Evropom različitim teritorijalnim i pomorskim pravcima, promovisana je od strane Si Đinpinga, predsednika Narodne Republike Kine, tokom posete Kazahstanu, septembra, i Indoneziji, oktobra 2013. godine. ${ }^{1}$ "Pojas i put” predstavlja ne samo novu razvojnu strategiju NR Kine na globalnom planu, već $u$ isto vreme i ponudu za saradnju i razvoj velikog broja država koje se nalaze na pravcima realizacije ovog grandioznog projekta. ${ }^{2}$ Izgradnja infrastrukturnih projekata (putnih i železničkih pravaca), realizacija projekata u oblasti energetike, industrije, nauke, obrazovanja, informisanja i dr. ${ }^{3}$ predstavljaju jaku osnovu za ekonomski i društveni razvoj zemalja članica projekta i unapređenja saradnje među državama, ne samo u njihovim bilateralnim odnosima, uključujući i njihove odnose sa NR Kinom, već i saradnju na regionalnom planu u okviru projekata koji uključuju više susednih država. Po svom razvojnom karakteru, ponudom za saradnju država koja podrazumeva dobrovoljnost a ne obaveznost, uzajamnu dobrobit za sve učesnike i različite benefite za građane, „Pojas i put” ima u isto vreme veliki značaj za unapređenje mira i bezbednosti u svetu.

O ogromnom globalnom značaju „Pojasa i puta” najbolje govori broj država koje učestvuju u projektu. U vreme kada je „Pojas i put” promovisan (2013. godine) obuhvatioje ukupno 65 država koje su se nalazile na pravcima

$1 \quad$ "Work Together to Build the Silk Road Economic Belt" (Part of the Speech at Nazarbayev University, Astana, Kazahstan); "Work together to Build a 21 - century Maritime Silk Road" (Part of the speech at the People's Representative Council of Indonesia); XI JINPING, The Governance of China, Foregn Languages Press, Beijing 2014, pp. 315-319, 320-324.

2 Na osnovu predloga predsednika Si Đinpinga i uzimajući u obzir stare (istorijske) teritorijalne i pomorske pravce „Puta svile”, Kina je odredila pet pravaca unutar „Pojasa i puta”. Ekonomski pojas „Puta svile” ima tri pravca: jedan od severozapadne Kine i severoistočne Kine do Evrope i Baltičkog mora, preko centralne Azije i Rusije; jedan od severozapadne Kine do Persijskog zaliva i Sredozemnog mora, prolazeći kroz centralnu Aziju i zapadnu Aziju; i jedan od jugozapadne Kine kroz Indokinesko poluostrvo do Indijskog okeana. Pomorski „Put svile” 21. veka ima dva glavna pravca: jedan koji počinje od priobalnih luka Kine, preko Južnokineskog mora, prolazi do Indijskog okeana i produžava do Evrope; drugi počinje od priobalnih luka Kine, prolazi Južno kinesko more i produžava do Južnog Pacifika. Building the Belt and Road: Concept, Practice and China's Contribution, Office of the heading Group for the Belt and road Initiative, May 2017, Foreign Languages Press Co. Ltd, Beijing, China, 2017.

3 Oblasti saradnje država unutar Inicijative „Pojas i put” su brojne i obuhvataju širok spektar konkretnih projekata: izgradnja železnice, autoputeva, luka, informacionih i telekomunikacionih objekata, naftne, gasne i energetske infrastrukture, mrežu zona slobodne trgovine, olakšanje međusobne trgovine, investiranja, finansijske saradnje, saradnje o ekološkoj i zaštiti životne sredine, obrazovanje, nauka, kultura, zdravlje, turizam, razmena ljudi i dr. Ibidem, pp. 18-48. 
povezivanja tri kontinenta: Azije, preko Afrike sa Evropom. ${ }^{4}$ „Pojas i put” je tada, prema broju država učesnica projekta, obuhvatao prostor od $51.491 .201 \mathrm{~km}^{2}$, na kome je živelo više od 4.400.000.000 ljudi. ${ }^{5} \mathrm{U}$ međuvremenu, broj država zainteresovanih za učešće u projektu je povećan. Na (prvom) Forumu „Pojas i put” održanom maja 2017. godine u Pekingu učestvovali su, kao učesnici ili posmatrači, predstavnici oko 100 država, među kojima je bilo i 29 predsednika država, kao i predstavnici 70 međunarodnih organizacija. ${ }^{6}$ Značaj „Pojasa i puta” na globalnom planu i njegov uticaj na razvoj velikog broja država u međunarodnoj zajednici prepoznala je i Organizacija ujedinjenih nacija, koja je podržala ovaj veliki razvojni projekat. Između Narodne Republike Kine i 39 država i međunarodnih organizacija potpisani su ugovori o saradnji i međusobnoj podršci realizaciji ciljeva koji su postavljeni u „Pojasu i putu” i usaglašavanju planova infrastrukturnog razvoja država potpisnica sa sadržajem ovog projekta. ${ }^{7}$

Značaj „Pojasa i puta” na globalnom planu može se bolje razumeti ukoliko se sagleda položaj i uloga NR Kine u svetskoj zajednici, podaci o njenoj ekonomskoj snazi, vojnoj moći i političkom uticaju.

NR Kina je jedna od pet stalnih članica Saveta bezbednosti Ujedinjenih nacija sa pravom veta, što je čini važnim i uticajnim činiocem rešavanja svih pitanja od značaja za funkcionisanje međunarodne zajednice. U oblasti ekonomije otvaranje Kine prema svetu, naročito krajem prošlog veka, uvođenje tržišnih mehanizama, uz reforme na unutrašnjem planu, označili su početak privrednog razvoja, sa godišnjim stopama rasta koje su kinesku ekonomiju učinili među najjačima u svetu. ${ }^{8}$ Prema podacima Svetske banke

4 Wang Yiwei. The Belt and Road Initiative - What will China offer the world in its rise, New World Press, Beijing, 2016, p. 76.

http.worldbank.org

$6 \quad$ Samit koji menja svet: Evo šta se sve događalo na Forumu „Pojas i put” u Pekingu i s kim se sve sastao Aleksandar Vučić, www. Espreso. Rs > politika> strana, Vreme 1376 Forum „Jedan pojas jedan put” u Pekingu: Novi put svile, www.vreme.com $>$ cms $>$ view

$7 \quad$ Prof. dr Žarko Obradović. „Pojas i put”: Balkanska perspektiva (političko-bezbednosni aspekti), Zbornik Novi put svile: balkanska perspektiva (političko-bezbednosni aspekti), Fakultet bezbednosti, Čigoja štampa, Beograd 2017, str. 84.

Building the Belt and Road: Concept, Practice and China's Contributiion, Ibid., pp. 7-8.

8 Prema podacima Kineskog zavoda za statistiku, realni godišnji privredni rast ( $\mathrm{u} \%)$ Kine u periodu od 1993. do 2003. godine iznosio je u proseku 9,57\% po godini. Od 2003. do 2010. privredni rast bio je prosečno godišnje 10,15\%. Rast BDP-a Kine je narednih godina bio nešto niži (u 2011 - 9,2\%, 2012. i 2013 - 7,7\%, u $2014-7,4 \%$, u 2015 - 6,9\%, u 2016. ciljana stopa rasta bila je između 6,5 i 7\%, dok je u 2017. god. iznosila 7,1\%. Janković Aleksandar. Privredni razvoj Kine: povezivanje na kineski način, Centar za istraživanje povezivanja Puta svile - CIPO, Beograd 2017, str. 48-54; Li Mančang. Tradicionalno prijateljstvo otvara novo poglavlje, saradnjom i zajedničkim naporima težimo prosperitetu, Priče o Kini, Politika 2. mart 2018, str. 10. 
za 2016. godinu, ekonomija NR Kine je po visini društvenog bruto proizvoda bila na drugom mestu u svetu (posle Sjedinjenih Američkih Država). ${ }^{9}$ Procena ekonomskih stručnjaka je da će privredni rast Kine i dalje biti „intenzivan i visok", što je, uz ekonomski napredak u proteklim decenijama, učinilo da Kina bude „vodeća privreda s tržištem u nastajanju” ${ }^{10}$ i važnom ulogom u ekonomskim odnosima u svetskim razmerama u budućem vremenu. Rast ekonomske moći Kine u svetskim razmerama potvrđuju i podaci o učešću Kine u svetskom izvozu (u \%) koje je sa 1,8\%, koliko je iznosilo 1990, naraslo na 12,1\% u 2013. godini. ${ }^{11}$ I prema snazi vojne moći NR Kina je među prvim zemljama sveta. Prema izveštaju koji je napravio "Global Firepower Index" na osnovu analize 50 različitih kriterijuma, NR Kina je bila na trećem mestu vojnih sila, iza SAD i Rusije. ${ }^{12}$

„Pojas i put” povezuje prostor i države od Azije (Kina), preko Afrike, do Evrope. U evropskom delu teritorije „Pojas i put” obuhvata prostor od severa do juga Evrope (Baltičkog mora do Mediterana), ali i njen zapadni deo, uključujući brojne železničke i putne (horizontalne i vertikalne) pravce. ${ }^{13}$ Jedan broj železničkih pravaca koji počinju u Kini a završavaju u više evropskih gradova, kao na primer u Roterdamu (Holandija), Duizburgu, Hamburgu, Frankfurtu (Nemačka), Madridu (Španija) i dr., čine i ove zemlje delom "Pojasa i puta". ${ }^{14} \mathrm{Na}$ svom zapadnom pravcu prostiranja, unutar Evrope, „Pojas i put" obuhvata i prostor Balkana i to ne samo teritorijalnim, nego i pomorskim pravcem. Kopneni deo veze „Pojasa i puta” i prostora Balkana obuhvata različite projekte pre svega u oblasti infrastrukture i energetike (a onda i u drugim oblastima), sa državama Balkana koje su deo saradnje Kine sa 16 država Centralne i Istočne Evrope (tzv. Proces saradnje 16+1), koji čini deo „Pojasa i puta”. Šesnaest evropskih država članica Procesa saradnje $16+1$ obuhvataju prostor veličine $1.348 .684 \mathrm{~km}^{2}$, na kom živi

9 Društveni bruto proizvod NR Kine je, prema podacima Svetske banke za 2016. godinu, iznosio 11.199.145 dolara. Ispred Kine su bile Sjedinjene Američke Države, čiji je BDP iznosio 18.625.475 dolara, dok je na trećem mestu bio Japan sa 4.940.159 dolara. World Development Indicator databasa, World Bank, December 17, 2017.

10 Janković Aleksandar, nav. delo, str. 94.

11 Isto, str. 97

12 Među brojnim podacima za 2016. godinu koji govore o vojnoj moći NR Kine treba istaći da NR Kina ima 2.335.000 aktivnih vojnika i još toliko u rezervi, da ima 9.150 tenkova, 4.788 oklopnih vozila, 2.942 aviona, 802 helikoptera i dr. Najmoćnije vojne sile sveta: Evo ko je jači - Amerika ili Rusija i Srbija ili Hrvatska; https://www.globalfirepower. com/countries - listing.asp, Pristupljeno 13.03.2017.

13 Do kraja 2016. godine Kina je otvorila 39 železničkih pravaca između Evrope i Kine, što uključuje oko 3.000 vozova prema 14 gradova u 9 evropskih zemalja. Žarko Obradović, Bilding the Belt and Road: Concept, Practice and China's Contri-bution, Ibidem, p. 13.

14 Wang Yiwei. The Belt and Road Initiative - Vhat will China offer the world in its Rise, New Woorld Press, Beijing, 2016, p. 63, 77. 
119.400.000 stanovnika. Na prostoru Istočne Evrope prema Aziji, unutar 6 država uključenih u Inicijativu „Pojas i put”, na prostoru od $1.031 .083 \mathrm{~km}^{2}$ živi 74.000.000 ljudi. ${ }^{15}$ Infrastrukturni projekti koji čine deo „Pojasa i puta” na prostoru Evrope obuhvataju još jedan broj država (pored pomenutih) koje nisu bile uključene kao učesnice ovog velikog projekta u trenutku njegovog nastanka.

Odnosi Evropske Unije sa NR Kinom su dominantno opredeljeni ekonomskom saradnjom, dok su politička pitanja objektivno u drugom planu. NR Kina je jedan od najvažnijih ekonomskih partnera Evropske unije (drugi najvažniji partner EU su Sjedinjene Američke Države). Vodeće zemlje EU, i bilateralno posmatrano, imaju visok nivo trgovinske razmene sa NR Kinom koji je godinama unazad u stalnom porastu, uz deficit na evropskoj strani.

Odnosi Kine i Evropske unije su dugotrajni i veoma važni za obe strane. Diplomatske odnose sa Evropskom ekonomskom zajednicom (EeZ), koja je preteča Evropske unije, Kina je uspostavila još 1975. godine. Sastanci vodećih ljudi NR Kine i Evropske unije održavaju se godišnje, počev od 1997. godine i to naizmenično u Briselu i Pekingu. Od 2003. godine obe strane su međusobne odnose okarakterisale izrazom "strateško partnerstvo", a od 2007. „sveobuhvatno strateško partnerstvo" ${ }^{16}$. Dok su politički odnosi između NR Kine i Evropske unije imali svoje periode zahlađenja zbog ocena EU o nekim unutrašnjim pitanjima Kine, pre svega o „ljudskim pravima” ${ }^{17}$, ekonomski odnosi su se stalno unapređivali, kako kroz strukturu roba koje su bile predmet međusobne privredne saradnje, tako i kroz obim razmene. Od skromne međusobne trgovine, čiji je obim 1975. godine iznosio oko 2.400.000.000 dolara ${ }^{18}$, i gde je Kina bila u donjem delu na lestvici spoljnotrgovinskih partnera Unije, godine 2014. NR Kina je postala najznačajniji partner EU po količini uvezene robe, a za EU na drugom mestu po količini robe koju je EU izvezla u neku zemlju (posle Sjedinjenih Američkih Država). Međusobnu trgovinsku razmenu između EU i NR Kine karakteriše deficit Evropske unije koji se, počev od sredine devedesetih godina prošlog veka, stalno povećavao ${ }^{19}$ i koji je 2014. godine iznosio 137.700.000.000 evra (nešto više nego 2013, kada je iznosio 131.900.000.000 evra) ${ }^{20}$.

15 http.worldbank.org

16 Blagoje S. Babić. Odnosi Kine i Evropske unije: geoekonomska osovina u razvoju, Međunarodna politika, broj 3, Beograd 2010, str. 418-462.

Isto, str. 427-428.

Isto, str. 343.

9 Blagoje S. Babić. Odnosi Kine i Evropske unije: geoekonomska osovina u razvoju, $M e-$ Aunarodna politika, broj 3, Beograd 2010, str. 451.

20 Bendini Roberto - Barone Barbara, "Trade and Economic relations with China 2015", European Parliament, Directorate - General for external policies, Policy Department, 2015, p. 9. 
Ekonomska saradnja sa NR Kinom je od velikog značaja za Evropsku uniju, stanje ekonomija država članica i život njihovih građana. Gotovo sve članice EU, pogotovu one najveće, nastoje da što više unaprede obim i sadržaj ekonomske saradnje sa NR Kinom. Najbolji pokazatelj toga je značaj koji evropske zemlje daju međusobnim posetama na najvišem nivou, kao što je poseta predsednika NR Kine Si Đinpinga Velikoj Britaniji novembra 2015. god. ili poseta Emanuela Makrona, predsednika Francuske, NR Kini januara 2018. godine i, naravno, broj i ekonomski značaj ugovora koje su Velika Britanija i Francuska potpisale sa NR Kinom. ${ }^{21}$

Kineske kompanije su se u poslednjoj deceniji na tržištu zemalja EU pojavile i kao važan činilac kupovine i razvoja pojedinih preduzeća u različitim oblastima privređivanja.

Evropska unija je na različite načine uključena u realizaciju projekta „Pojas i put”. Deo saradnje EU sa Kinom i institucionalne povezanosti sa „Pojasom i putem” predstavlja učešće 11 država, članica Evropske unije ${ }^{22}$ u procesu saradnje NR Kine sa 16 zemalja Centralne i Istočne Evrope, koje je započeto 2012. godine, održavanjem Samita procesa saradnje u Varšavi (Poljska). U proteklim godinama sve ove zemlje su, zajedno sa NR Kinom započele (i ostvarile) veliki broj projekata iz različitih oblasti i ujedno unapredile bilateralne odnose i saradnju sa Kinom, u čemu prednjače Poljska, Češka i Mađarska. ${ }^{23}$ Da ova saradnja predstavlja deo kinesko-evropskih odnosa ali

${ }^{21}$ Dobar primer nastojanja država članica EU da se što više unapredi saradnja sa NR Kinom jesu posete na najvišem nivou i vrednost potpisanih ugovora o saradnji sa Kinom. Predsednik NR Kine Si Đinping je posetio Veliku Britaniju novembra 2015. god. i tada je potpisano čak 150 poslovnih sporazuma vrednih gotovo 40.000.000.000 funti (62.000.000.000 dolara), a premijer (tadašnji) Vel. Britanije je objavio početak „zlatne epohe" u odnosima između dve zemlje. Vreme 1296 - Velika Britanija - Kina - Nova faza... Početak zlatnog doba; httpsi//www.vreme.com. Istog karaktera je i poseta predsednika Francuske Emanuela Makrona NR Kini, januara 2018. godine, kada je dogovorena nabavka 184 aviona Erbas A 320, čija je vrednost 18.000.000.000 evra. U delegaciji E. Makrona bilo je i oko 50 poslovnih ljudi iz Francuske. Politika online - Makron: Kina će kupiti 184 Erbasova aviona - Politika, www.politika, RS $>$ scc $>$ clanak $>$ Makron 10.01.2018, Makron stigao u trodnevnu posetu Kini / N1 Srbija, 08.01.2018., www. RS n1 info.com $>$ Svet,svet $>$ Makron...

22 Države, članice Evropske unije koje učestvuju u procesu saradnje NR Kine sa 16 zemalja Centralne i Istočne Evrope su: Poljska, Litvanija, Letonija, Estonija, Češka, Slovačka, Mađarska, Slovenija, Hrvatska, Rumunija i Bugarska. Ostalih pet članica su države kandidati za članstvo u Evropsku uniju: Srbija, Albanija, Crna Gora, Bosna i Hercegovina i Makedonija.

23 Dr Long Jing. Budućnost saradnje između Kine i Balkana i njene mogućnosti u okviru „Saradnje 16+1" i Inicijative „Pojas i put”, Zbornik Novi put svile: Balkanska perspektiva - političko-bezbednosni aspekti, Fakultet bezbednosti, Čigoja štampa, Beograd 2016, str. 9-19. Dr Liu Zuokui. „Saradnja 16+1" u kontekstu Inicijative „Pojas i put”, Zbornik Novi put svile: Balkanska perspektiva političko-bezbednosni aspekti, nav. delo, str. 43-68. 
i deo „Pojasa i puta” potvrđuje činjenica da se Proces saradnje 16+1 (znači i prostor zemalja članica EU) nalazi na zapadnom pravcu kineske inicijative, kao i sadržaj dokumenata usvojenih na održanim godišnjim sastancima. Četvrti samit Procesa saradnje 16+1, održan u Sudžou (Kina) 2015. godine, u usvojenim dokumentima potvrđuje opredeljenje država članica o potrebi „evroazijskog povezivanja”, tj. „povezivanja Kine i Evrope na kopnu, moru i vazduhu kroz ključne transportne koridore, veze i projekte"24. Isti cilj, povezivanja Kine i Evrope, sadrži i Inicijativa „Pojas i put”.

Nameru EU i NR Kine da još više unaprede međusobnu ekonomsku saradnju, ali i da uvaže interese obeju strana i naprave sinergiju „Pojasa i puta" (uključujući i Proces saradnje 16+1) i planova infrastrukturnog razvoja zemalja članica Evropske unije potvrđuju i zajednički potpisani dokumenti i preduzete aktivnosti. Kineska vlada i Evropska komisija potpisale su Memorandum o razumevanju i pokrenule saradnju na izradi Platforme za povezivanje EU i Kine. ${ }^{25}$ Evropski planovi infrastrukturnog razvoja, tj. realizacija Investicionog plana za Evropu (tzv. Junkerov plan iz 2015. godine) dobili su saglasnost Kine, uz najavu finansijske podrške. ${ }^{26}$ Januara 2016. god. Kina se pridružila Evropskoj banci za obnovu i razvoj (EBRD) sa namerom da unapredi saradnju sa bankom u više oblasti, uključujući zajedničko finansiranje i koordinaciju politike. ${ }^{27}$ Činjenica da su se Velika Britanija, Francuska, Nemačka i Italija pridružile Azijskoj infrastrukturnoj investicionoj banci, koja je osnovana za finansiranje infrastrukturnih projekata, potvrđuje globalni karakter Inicijative „Pojas i put” i zainteresovanost ovih država za učešće u Projektu. ${ }^{28}$

Koordinacija saradnje i planova razvoja utvrđena je i na normativnom planu. Dokumenta iz Sudžoa, sa Četvrtog samita Procesa saradnje 16+1, konstatuju da je ta saradnja „u skladu sa EU zakonodavstvom, propisima i politikama koje proizlaze iz članstva u EU"29. I dokumenta sa 6. samita, održanog u Budimpešti (Mađarska), 2017. godine, takođe potvrđuju obavezu

24 „Srednjoročni plan saradnje Kine i zemalja Centralne i Istočne Evrope”, Sudžou, Kina, 24. novembar 2015. godine. Preuzeto sa: www.chine - ciec.org, 01/08/2016. Žarko Obradović, Strateško partnerstvo „male” Srbije i „velike” Kine, Srpska politička misao, broj 3/2016, Beograd, str. 132.

25 Building the Belt and Road, Ibidem, p. 18.

26 European Commission - Press releases - Investment plan for Europe gaes global: China announces its contribution to \# invest EU; http://eeas.europa.eu/china/ Building the Belt and Road, Ibidem, p. 31.

Wang Yiwei, Ibidem, p. 77.

„Srednjoročni plan saradnje Kine i zemalja Centralne i Istočne Evrope”, Isto. 
saradnje svih država učesnica Procesa saradnje 16+1 u skladu sa „zakonima, propisima, standardima... i politikom EU za članice i zemlje kandidate". ${ }^{30}$

Da Evropska unija „detaljno prati” šta sve čini sadržaj Proces saradnje NR Kine sa zemljama Centralne i Istočne Evrope potvrđuje i činjenica da je EU učestvovala u radu Šestog samita Procesa saradnje 16+1 u Budimpešti (Mađarska) 2017. godine u svojstvu posmatrača. ${ }^{31}$

Evropska unija je, u odnosu na osnivanje i rad Procesa saradnje 16+1, od početka pokazivala određenu uzdržanost. Posle Prvog samita, održanog u Varšavi 2012. god., prilikom formiranja Sekretarijata za saradnju, septembra 2012. godine u Pekingu, među zemljama učesnicama a koje su članice Evropske unije, samo su Slovačka i Hrvatska bile zastupljene na ministarskom nivou, dok su ostale članice EU bile zastupljene na nižem nivou (državni sekretari, pomoćnici ministara i dr.). ${ }^{32}$ Sa početkom realizacije projekata, kao dela Procesa saradnje 16+1, Evropska komisija je nekim svojim članicama postavila pitanje usaglašenosti procedura realizacije projekata sa zakonodavstvom (propisima) Evropske unije. Iako je u svim dokumentima usvojenim na samitima Procesa saradnje 16+1 apostrofirana potreba usklađivanja svih odluka koje se donose (u okviru saradnje ovih država sa NR Kinom) sa zakonodavstvom Evropske unije, neki postupci sa strane EU ukazuju na mogući spor sa NR Kinom u realizaciji određenih projekata, kako sa zemljama članicama EU tako i državama kandidatima za članstvo u EU, koje učestvuju u projektu.

Dok očigledno, sa jedne strane, pojedine evropske zemlje, članice EU u okviru bilateralne saradnje, nastoje da unaprede ekonomsku saradnju sa NR Kinom i bolji položaj (i profit svojih kompanija), dotle, sa druge, EU u poslednje vreme nastoji da administrativnim merama kontroliše i uspori aktivnosti kineskih kompanija na celom prostoru Evrope, kako među državama članicama tako i među zemljama kandidatima za članstvo u Evropskoj uniji, kao i realizaciju pojedinih infrastrukturnih projekata.

Tako je prilikom kupovine srpske železare u Smederevu od strane kineske kompanije „Hestil” Evropska komisija vršila proveru da li kupovina železare ugrožava proizvodnju (i cenu čelika) kompanija unutar zemalja članica EU. Izveštaj Komisije nije doveo u pitanje kupovinu i rad železare u

30 The Budapest Guidelines for Cooperation between China and Central and Eastern European Countries, 27/11/2017, www.chine-cier.org.

31 The Budapest Guidelines for Cooperation between China and Central and Eastern European Countries, 27/11/2017, www.chine-circ.org.

32 Autor ovog teksta učestvovao je u radu Sekretarijata za saradnju između Kine i zemalja Centralne i Istočne Evrope, kao državni koordinator Republike Srbije za proces saradnje Kine - zemlje Centralne i Istočne Evrope, tako da je mogao da se neposredno upozna sa nivoom zastupljenosti svake države učesnice sastanka. 
Srbiji ${ }^{33}$, ali je pokazao nameru EU da reaguje u slučajevima kada kupovina neke evropske kompanije (ili dela) od strane kineskih kompanija „ugrožava evropske interese". I ugovor o rekonstrukciji i izgradnji železničke pruge između Mađarske, Srbije i Kine, potpisan na samitu u Bukureštu 2013. godine, izazvao je „pažnju” EU. Sa početkom realizacije ovog projekta od strane Evropske unije je prema Mađarskoj, kao zemlji članici, postavljen zahtev poštovanja propisa EU pri raspisivanju javnog tendera za odabir kompanije koja će realizovati projekat izgradnje pruge. Evropska komisija je, kao i u slučaju kupovine i rada železare u Smederevu, povela istragu sa ciljem da utvrdi da li Mađarska, kao zemlja članica EU, krši zakon EU o konkurentnosti kada je reč o javnim tenderima za velike transportne projekte. ${ }^{34}$ Pored toga, reagovanje dela nemačkih privrednika i političara na kupovinu robotike firme „Kuka” od strane kineske kompanije „Midea” (da je reč o osetljivoj tehnologiji, što dovodi u pitanje opravdanost prodaje), na ponudu kineske državne elektrodistribucije da kupi deo nemačkog operatera „Hertz”, kao i na nameru kineske kompanije „Gili” da poveća na 10\% svoj udeo u kompaniji „Dajmler” (i time stekne mogućnost da raspolaže tehnologijom za baterije električnih automobila), uz tvrdnju da se tako može usporiti ekonomski napredak zemlje i, sa druge strane, dati mogućnost drugoj strani (kineskim kompanijama) da raspolažu i koriste najnovije tehnologije, podstaklo je i druge članice EU da „obrate pažnju” na ulaganja iz NR Kine. Nemačka, Francuska i Italija su na nivou EU pokrenule inicijativu da se usvoje mehanizmi za kontrolu investicija iz Kine i drugih zemalja. ${ }^{35}$

Proces saradnje 16+1, pored nekoliko zemalja Centralne i Istočne Evrope $^{36}$, uključuje i devet država Balkana, i to: Sloveniju, Hrvatsku, Bosnu i Hercegovinu, Srbiju, Crnu Goru, Albaniju, Makedoniju, Bugarsku i Rumuniju. Pomorski deo veze „Pojasa i puta” sa Balkanom predstavlja grčka luka Pirej na Mediteranu, kao važna destinacija za transport robe na Balkanu i u Evropi. Na taj način i Grčka je, kao balkanska zemlja koja nije član Procesa saradnje 16+1, ali učestvuje na godišnjim konferencijama ovog projekta,

33 Žarko Obradović, „Pojas i put”, Balkanska perspektiva (političko-bezbednosni aspekti), Zbornik Novi put svile: Balkanska perspektiva (političko-bezbednosni aspekti) /priredio V. Cvetković; uredništvo Šao Binhong...../Beograd, Fakultet bezbednosti, 2017 (Čigoja štampa), str. 95.

34 EU i dalje razmatra da li je pruga Beograd - Budimpešta u skladu sa Zakonima Unije, www.politika.RS>scc>članak>EU-i-dalje... 27. 11. 2017.

35 Kavaja J., Kina ugrožava industrijsku dominaciju Nemačke, Politika, 7. maj 2018, Spoljna politika RS, str. 3.

36 Proces saradnje Kine sa zemljama Centralne i Istočne Evrope obuhvata, pored Kine, i 16 evropskih država: Mađarsku, Bugarsku, Rumuniju, Poljsku, Srbiju, Bosnu i Hercegovinu, Hrvatsku, Sloveniju, Slovačku, Albaniju, Makedoniju, Crnu Goru, Češku, Litvaniju, Letoniju i Estoniju. 
kao što je bio slučaj na Samitu u Budimpešti novembra 2017. godine, uključena u realizaciju „Pojasa i puta”.

Saradnja balkanskih država sa NR Kinom do početka realizacije Procesa saradnje 16+1 dominantno je bila bilateralnog karaktera, odvijala se kroz privrednu saradnju i bez infrastrukturnih projekata koji bi uključili (neku) treću zemlju. Proces saradnje 16+1 je promenio takvo stanje, i u bilateralnoj saradnji i na regionalnom planu. Balkanske zemlje su dobile novo mesto i veći značaj u saradnji NR Kine sa evropskim državama. Od šest do sada održanih sastanaka NR Kine sa 16 država sa zemljama Centralne i Istočne Evrope ${ }^{37}$, dva su održana u državama Balkana. Drugi samit Procesa saradnje 16+1 održan je u Rumuniji (Bukureštu) 2013, a Treći u Srbiji (Beogradu) 2014. godine. Predstojeći, Sedmi samit saradnje ponovo će se održati u jednoj balkanskoj državi tokom 2018. godine. Ovog puta domaćin Samita biće Bugarska (Sofija). Sa balkanskim državama NR Kina je unutar ovog procesa zaključila veliki broj ugovora, u najvećem delu bilateralnog karaktera, ali i jedan broj regionalnog karaktera. Među ugovorima koji su potpisani ili je započeta njihova realizacija značajem se ističu brojni projekti u oblasti infrastrukture (izgradnja železničkih i putnih pravaca), projekti u oblasti energetike (rekonstrukcija i izgradnja termoelektrana), ali i u drugim oblastima. U Bukureštu je 2013. godine potpisan ugovor o rekonstrukciji i izgradnji brze pruge Beograd - Budimpešta (za putnički i transportni saobraćaj) između Mađarske, Srbije i Kine, čija realizacija je u međuvremenu i započeta. Kineske kompanije u Crnoj Gori izvode radove na izgradnji autoputa koji bi povezao pomorski deo Crne Gore sa Srbijom (autoput Beograd - Južni Jadran). Radovi na izgradnji ovog autoputa i povezivanju Srbije i Crne Gore već uveliko se izvode i sa srpske strane, a dogovorena je sa kineskim kompanijama izgradnja i zadnje (najduže) deonice kroz Srbiju, do granice sa Crnom Gorom. Dogovorena je izgradnja autoputa u Makedoniji, dok se istovremeno razgovara sa Albanijom o izgradnji autoputa koji bi povezao Albaniju sa Makedonijom. Broj i struktura projekata regionalnog karaktera u narednim godinama biće još veći na šta ukazuje najava realizacije hrvatske inicijative „Tri mora” o „uspostavljanju saradnje u oblasti infrastrukture, logistike i povezivanja luka Baltičkog, Jadranskog i Crnog mora" ${ }^{38}$, kao i povezivanje putnim pravcem prostora Grčke (luke Pirej), preko Makedonije, sa Srbijom (Beograd) i dalje na sever. Pored infrastrukturnih

\footnotetext{
37 Unutar Procesa saradnje Kine sa zemljama Centralne i Istočne Evrope, od osnivanja do današnjih dana održano je šest samita i to u: Poljskoj (Varšava) 2012. god., Rumuniji (Bukurešt) 2013, Srbiji (Beograd) 2014, Sudžou (Kina) 2015, Letoniji (Riga) 2016. i Mađarskoj (Budimpešta) 2017. godine.

38 Žarko Obradović. „Pojas i put” Balkanska perspektiva (političko-bezbednosni aspekti), Zbornik radova, nav. delo, str. 89-90.
} 
projekata, saradnja postoji i u drugim oblastima. Bosna i Hercegovina je, primera radi, u saradnji sa NR Kinom, već završila izgradnju termoelektrane u Stanarima, a dogovorena je i izgradnja nove termoelektrane. Makedonija je dogovorila izgradnju hidroelektrane, a Rumunija je započela projekat saradnje o oblasti energetike, koja podrazumeva i projekte o izgradnji nuklearnih elektrana.

Realizacija postojećih i novih projekata biće olakšana osnivanjem različitih asocijacija (centara) u državama Balkana. U Srbiji je, primera radi, planirano osnivanje Centra za saradnju u oblasti saobraćaja i infrastrukture, u Rumuniji Centra za energetiku, u Sloveniji Centra za šumarstvo i dr. Proteklih godina (od 2012. god. pa nadalje) balkanske države su bile domaćini skupova o saradnji u različitim oblastima: poljoprivrede, trgovine, privrede, turizma, kulture, obrazovanja i dr. ${ }^{39}$

Samo tokom 2017. godine u državama Balkana održani su brojni skupovi, kao deo smernica sa Samita iz Rige za saradnju Kine sa 16 zemalja Centralne i Istočne Evrope.

Republika Srbija među zemljama članicama Procesa saradnje 16+1, što uključuje i balkanske zemlje, daleko prednjači u kvalitetu bilateralnih odnosa sa NR Kinom, broju i vrsti različitih projekata koji su dogovoreni između dve zemlje, započeta njihova realizacija ili su već završeni. Međudržavni odnosi između Srbije i Kine su na najvišem mogućem nivou. Strateško partnerstvo, koje postoji od 2009. godine, prošireno je 2013, a od juna 2016. podignuto na još veći nivo - nivo „sveobuhvatnog strateškog partnerstva" ${ }^{4}$. Najviši predstavnici dveju država (predsednici republika, predsednici vlada, predsednici parlamenata, ministri i dr.) u proteklih nekoliko godina ostvarili su brojne međusobne posete. ${ }^{41}$

Isto, str. 90

Žarko Obradović. Strateško partnerstvo „male” Srbije i „velike” Kine - Unutrašnji i međunarodni aspekti saradnje, Srpska politička misao, Institut za političke studije, broj 3/2016, Beograd 2016, str. 128.

41 Predsednik NR Kine Si Đinping je boravio u zvaničnoj poseti Srbiji juna 2016. godine, kada je potpisan sporazum o uspostavljanju „sveobuhvatnog strateškog partnerstva” između Srbije i Kine, kao i još 21 sporazum o međusobnoj saradnji. Pre toga, predsednik Vlade NR Kine L. Kećijang je novembra 2014. godine posetio Srbiju. Predsednik svekineskog narodnog kongresa V. Deđijang je posetio Srbiju juna 2017. godine. Predsednik Republike Srbije A. Vučić je više puta u zadnjih nekoliko godina posetio NR Kinu, kao predsednik države i pre toga kao predsednik Vlade Republike Srbije: maja 2017. godine, prilikom učešća na Forumu „Pojas i put”, održanom u Pekingu, novembra 2015. na Četvrtom samitu Procesa saradnje, održanom u Su Džou i dr. Predsednica Narodne skupštine Srbije M. Gojković boravila je u zvaničnoj poseti Svekineskom narodnom kongresu NR Kine novembra 2017. godine. 
Srbija je član Procesa saradnje Kine sa 16 zemalja Centralne i Istočne Evrope od osnivanja, 2012. godine, i jedan je od najaktivnijih članova ovog procesa. Prilikom osnivanja Sekretarijata Procesa saradnje, septembra 2012. u Pekingu, Srbija je predložila više od 50 projekata iz različitih oblasti kao predmet buduće saradnje. ${ }^{42} \mathrm{U}$ proteklih šest godina unutar ovog Procesa Srbija je ostvarila impozantne rezultate: započet je projekat revitalizacije i izgradnje pruge Budimpešta - Beograd (između Mađarske i Srbije), izgradnja više deonica na autoputu Beograd - Južni Jadran, izgradnja obilaznice oko Beograda, završena je revitalizacija bloka 2 Termoelektrane u Kostolcu i započeta izgradnja novog bloka 3, izvršena revitalizacija površinskog kopa Drmno, dogovorena izgradnja elektrane za proizvodnju električne energije od otpada, započet projekat obnovljivih energija u Srbiji ${ }^{43}$ i dr. Srbija (Beograd) je bila domaćin Trećeg samita Procesa saradnje 16+1 novembra 2014. godine. U Srbiji treba da bude osnovan Centar za saradnju Kine i zemalja Centralne i Istočne Evrope u oblasti saobraćaja i infrastrukture, što će značajno unaprediti realizaciju infrastrukturnih projekata kako u Srbiji tako i u regionu.

Na zadnjem samitu Procesa saradnje 16+1, održanom u Budimpešti novembra 2017. godine, potpisana su još četiri važna ugovora: o projektovanju i izvođenju radova na izgradnji još jedne deonice na autoputu Beograd - Južni Jadran (Preljina-Požega), o izgradnji toplo-dalekovoda između Obrenovca i Novog Beograda, o realizaciji projekta za obradu i odlaganje otpadnih voda iz centralnih delova Beograda, o uslovima potrebnim za izvoz goveđeg mesa u Kinu. ${ }^{44}$

Postoje i drugi elementi koji oslikavaju karakter i kvalitet veza između dve države. Narodna Republika Kina je jedan od stubova spoljne politike Srbije. Srbija je prva zemlja u Evropi gde je kineska kompanija završila jedan veliki infrastrukturni projekat (izgradnja mosta preko Dunava). Srbija je, takođe, prva zemlja u Evropi koja je donela odluku o ukidanju viza za putovanje za građane NR Kine prilikom posete Srbiji. Između Beograda i Pekinga uspostavljena je direktna avio-linija. Kineska kompanija „Hestil” je kupila srpsku železaru u Smederevu. Srbija je jedna od retkih zemalja u Evropi koja je na nivou osnovnih i srednjih škola uvela mogućnost učenja

$42 \quad$ Isto, str. 132.

43 Pregled sporazuma koji su potpisani tokom posete predsednika NR Kine Si Đinpinga Srbiji juna 2017. godine, Internet, http://www.srbija.gov.rs/vesti/php?id=267615, 18/6/2016. Žarko Obradović. Strateško partnerstvo „male” Srbije i „velike” Kine..., nav. delo, str. 130.

${ }_{44}$ Brnabić: Srbija u Budimpešti zagrizla najveći deo kolača, 27. 11. 2017. www.rts.rs>stori es $>$ story $>$ politika $>$...; Li. Nove tri milijarde dolara za zemlje CEe, Politika Online, www. politika.rs $>$ scc $>$ clanak $>$ Danas $-\ldots$ 
kineskog jezika. U Srbiji se, pored toga, kineski jezik uči na katedri Filološkog fakulteta Univerziteta u Beogradu. U Srbiji rade dva instituta Konfučije - u Beogradu i Novom Sadu. Dve zemlje su započele postupak otvaranja kulturnih centara: Kulturnog centra Kine u Beogradu i Kulturnog centra Srbije u Pekingu. Obe zemlje su objavile niz knjiga, publikacija, filmova, što sve doprinosi širenju saradnje i međusobnom razumevanju.

Saradnja Srbije sa Kinom u Procesu $16+1$ je značajna jer čini deo globalne kineske Inicijative „Pojas i put”. Da je Srbija posvećena realizaciji „Pojasa i puta" potvrda je i potpisivanje Memoranduma o razumevanju između Vlade NR Kine i Vlade Republike Srbije o zajedničkoj afirmaciji Inicijative „Pojas i put”, novembra 2015. godine, kao i dogovor dveju zemalja da zajednički rade na stvaranju veza između „Pojasa i puta” i svojih nacionalnih strategija razvoja..$^{45}$

Sve napred pomenuto doprinelo je da Srbija ima odlične odnose sa NR Kinom u različitim oblastima, da bude najaktivniji član Procesa saradnje $16+1$, a samim tim i važan deo Inicijative „Pojas i put” na prostoru Balkana. Srbija je za Kinu postala važan i najpouzdaniji partner u ovom delu Evrope i sveta. Činjenica da je Srbija zemlja kandidat za članstvo u Evropskoj uniji nije prepreka za razvoj odnosa između dve zemlje. Kina podržava put Srbije ka Evropskoj uniji, što je i logično jer i sama Kina ima izuzetno razvijene odnose sa EU. Iako je Srbija kao zemlja kandidat za članstvo u EU u obavezi da „sledi” politiku EU, kad je reč o odnosima sa Kinom Srbija potpuno autonomno odlučuje o svim pitanjima od značaja za kinesko-srpske odnose. To Srbiji daje prednost u odnosu na neke druge balkanske države koje su članice Evropske unije i koje moraju da svoju politiku, pa samim tim i saradnju sa Kinom, koordiniraju sa Briselom. Nivo uspostavljenog partnerstva sa Kinom nesumnjivo je ojačao međunarodni položaj Srbije kako u regionu tako i na širem planu međunarodnih odnosa.

Uzimajući u obzir globalni karakter Inicijative „Pojas i put”, broj zemalja koje su direktno ili indirektno iskazale interes da učestvuju u različitim oblicima saradnje unutar ovog Projekta (a to je više od polovine zemalja članica OUN), veličinu prostora (od Azije, preko Afrike, do Evrope) na kome će se realizovati brojni infrastrukturni, energetski i drugi projekti (koji uključuje veliki deo prostora Evrope i unutar toga teritoriju Balkana), odnose moći (vojne, ekonomske, političke i dr.) među državama u međunarodnoj zajednici, položaj i ulogu Kine u međunarodnim odnosima, karakter bilateralnih odnosa NR Kine sa tim državama, postoji nekoliko elemenata

$45 \quad$ Memorandum o razumevanju između Vlade Narodne Republike Kine i Vlade Republike Srbije o zajedničkoj afirmaciji Ekonomskog pojasa i puta svile i Pomorskog puta svile 21. veka, Službeni glasnik Republike Srbije - Međunarodni ugovori, br. 01/16. 
koji mogu zaustaviti ili usporiti realizaciju „Pojasa i puta” na Balkanu, ili sa pojedinim balkanskim državama.

Na globalnom, svetskom planu, sudbina „Pojasa i puta”, tj. potpuna realizacija infrastrukturnih, energetskih i drugih projekata zavisi primarno od odnosa NR Kine sa Sjedinjenim Američkim Državama (političkim, ekonomskim i vojnim pre svega). Uspon NR Kine u međunarodnim odnosima, kao i najava Si Đinpinga, Generalnog sekretara KP Kine i predsednika NR Kine izneta na 17. kongresu KP Kine, održanom oktobra 2017. godine, da je NR Kina spremna da 2050. godine preuzme ulogu globalnog lidera, logično osporava vodeće mesto SAD u međunarodnim odnosima koje je utemeljeno u periodu posle završetka Hladnog rata, devedesetih godina prošlog veka. U nameri da zadrži svoju poziciju na svetskoj sceni i da NR Kinu smatra svojim strateškim protivnikom kom se treba suprotstaviti, SAD će bez sumnje delovati, direktno ili preko drugih država svojih saveznika, različitim sredstvima, kako bi osporile mesto i ulogu Kine u međunarodnoj zajednici i time ujedno usporile ostvarenje „Pojasa i puta”, što su SAD pokazale vrlo brzo. Prilikom objavljivanja Nacionalne strategije bezbednosti SAD početkom decembra 2017. godine, predsednik Amerike D. Tramp je ocenio da je Kina (pored Rusije) revizionistička sila i konkurent koji nastoji da ospori moć Amerike i podrije njenu bezbednost i prosperitet. ${ }^{46}$ Isti odnos prema Kini kao strateškom protivniku potvrđen je od strane Ministarstva odbrane SAD januara 2018. godine, koji je objavio novu vojnu strategiju gde je Kina (takođe pored Rusije) označena kao glavni konkurent. Tom prilikom je istaknuto da je rivalstvo velikih sila, a ne terorizam, prioritet američke nacionalne strategije ${ }^{47}$ i da Amerika treba da se suprotstavi Kini. Da se nije ostalo samo na rečima Amerika je pokazala vrlo brzo, kroz odluku da se uvedu tarife na kineske proizvode, čime je otvoren trgovinski rat sa Kinom, kao i kroz optužbe Kine za militarizaciju ostrva u Južnom kineskom moru (koja Kina smatra svojom teritorijom).

Uprkos iznetim stavovima i preduzetim merama od strane SAD prema Kini, mala je verovatnoća da će doći do direktnog sukoba između dve zemlje zbog brojnih gotovo nesagledivih posledica takvog sukoba po ceo svet. Aktuelna dešavanja u međunarodnim odnosima, suprotstavljeni stavovi NR Kine i SAD prema pitanju pomorskih granica Kine u Južnom kineskom moru, kao i različiti pogledi (pristupi) pojedinih država prema Kini i projektu „Pojas i put” (npr. Pakistan i Indija), kao i direktni i indirektni odnosi SAD i Kine i njihovi (saveznički) odnosi sa trećim državama mogu

46 Amerika na prvom mestu - Tramp objavio nacionalnu strategiju: Mi smo u igri i pobedićemo, 18. 02. 2017, http://www.blic.rs/nznfll8, Pristupljeno 19. 12. 2017.

47 Nova vojna strategija SAD: Kina i Rusija glavni konkurenti, Politika, 20. 01. 2018., str. 3, spoljna@politika.rs 
da dovedu u pitanje sudbinu projekta „Pojas i put”. Čini se logičnim i gotovo izvesnim da će neke države koje se nalaze na pravcima (teritorijalnim ili pomorskim) ostvarenja "Pojasa i puta” biti pasivne u pogledu učešća u projektima koji čine „Pojas i put”, pri čemu će neučestvovanje biti „objašnjeno” različitim razlozima: graničnim sporovima, ekonomskim problemima, geografskim razlozima, bilateralnim odnosima i dr. Iz ovih razloga realizacija „Pojasa i puta" na prostoru od Azije i Afrike do Evrope može biti privremeno ili trajno osporena i zaustavljena.

Kada je o Balkanu reč, takva mogućnost, direktnog ili indirektnog sukobljavanja SAD i Kine, za sada, ne postoji. Dve zemlje imaju različit geopolitički pristup prema prostoru Balkana. Sjedinjene Američke Države od početka devedesetih godina prošlog veka direktno utiču na dešavanja na Balkanu i upravljaju određenim procesima. Takva, vodeća uloga SAD na zbivanja na Balkanu traje i u sadašnje vreme. Sjedinjene Američke Države su bile među prvim zemljama koje su priznale novostvorene države na prostoru bivše SFRJ, imale su glavnu ulogu u pregovorima o ustrojstvu Bosne i Hercegovine i potpisivanju Dejtonskog sporazuma 1995. godine, pregovorima u Rambujeu 1999. o rešavanju kosovskog pitanja, bombardovanju SR Jugoslavije (takođe 1999. godine), priznanju i promociji tzv. države Kosovo 2008. god., rešavanju otvorenih pitanja u regionu (u Bosni i Hercegovini i Makedoniji npr) i dr. Sjedinjene Američke Države imaju takođe i svoju ulogu i značaj (direktan i indirektan) i u pregovorima Beograda i Prištine, kao i pitanju prijema novih država u članstvo u Evropskoj uniji i dr. ${ }^{48}$

Kada je u pitanju prostor Balkana, ne treba očekivati direktno osporavanje prisustva i delovanja NR Kine od strane SAD, jer se prisustvo NR Kine na tim prostorima ne doživljava kao geopolitička pretnja, već prevashodno kao deo ekonomskih aktivnosti Kine. Moguće izvore sporova sa NR Kinom na ovim prostorima SAD će „rešavati” pre svega sa Evropskom unijom (ili preko EU). Da se prisustvo NR Kine na Balkanu ne smatra protivno geopolitičkim interesima SAD govori i Nacrt izveštaja NATO-a (u kome SAD imaju vodeću ulogu), tj. Političkog komiteta Parlamentarne skupštine NATO-a o bezbednosti na Zapadnom Balkanu, koji konstatuje da je prisustvo Kine u

48 Predstavnici administracije SAD prilikom njihovih zvaničnih poseta Srbiji gotovo uvek naglašavaju podršku Amerike Srbiji za članstvo u Evropsku uniju. Takve izjave bi bile logične same po sebi da nisu istovremeno praćene i stavovima da je pitanje nezavisnosti Kosova za njih neupitno i da Srbija treba to da prihvati. Predstavnici privremenih institucija Kosova, kao npr. predsednik takozvane Vlade Kosova R. Haradinaj, javno izjavljuju da Kosovo nema svoju spoljnu politiku već samo sledi ono što mu SAD kažu da treba učiniti. 
ovom području značajno povećano, posebno u Srbiji, i da je primarni interes NR Kine ekonomski a ne politički. ${ }^{49}$

Pozicija NR Kine prema prostoru Balkana je potpuno drugačija. NR Kina je u prošlosti imala razvijene bilateralne odnose sa pojedinim balkanskim državama, pre svega na političkom planu kao posledica ideološke bliskosti (i u NR Kini i nekim balkanskim državama na vlasti su bile komunističke partije), bez veće ekonomske saradnje. I tokom devedesetih godina prošlog veka, saradnja balkanskih država sa NR Kinom je, uz pojedine izuzetke (SR Jugoslavija primera radi), bila skromnog obima. Početkom XXI veka intenzivira se saradnja NR Kine i SR Jugoslavije (kasnije Srbije), a od ustanovljenja procesa saradnje Kine sa zemljama Centralne i Istočne Evrope prisustvo Kine na prostoru Balkana postaje značajnije i saradnja sa balkanskim državama dobija nove impulse i nove sadržaje. U državama Balkana, u saradnji sa NR Kinom, realizovan je deo projekta u oblasti infrastrukture i energetike, i potpisano je više bilateralnih ugovora iz različitih oblasti koji će biti realizovani narednih godina.

Situacija sa Evropskom unijom je drugačija. Dok, sa jedne strane, Evropska unija, na globalnom nivou, preko svojih organa, a i same države članice (pogotovu one ekonomski najjače) nastoje da povećaju ekonomsku razmenu sa Kinom, pogotovu svoje prisustvo na velikom kineskom tržištu, kao i da usaglase svoje planove infrastrukturnog razvoja (saobraćajne i železničke pravce), kao i projekte u oblasti energetike, sa sadržajem kineske Inicijative „Pojas i put”, sa druge, nastoje postepeno da „kontrolišu” prisustvo i uticaj kineskih kompanija na svom tržištu. Vodeće zemlje Evropske unije (Francuska, Nemačka i Italija) pokrenule su inicijative kroz nacrte pojedinih zakona kojima bi se „procenile, istražile, odobrile, zabranile ili poništile (podvukao Ž.O.) strane direktne investicije".$^{50}$ Pored toga, Evropska unija nastoji da se, donošenjem novih pravila, zaštiti od jeftinijeg uvoza iz Kine. ${ }^{51}$

Ovakvo delovanje Evropske unije će, bez sumnje, najviše pogoditi zemlje članice EU, pogotovu one koje su deo Procesa saradnje 16+1 (zemlje Centralne i Istočne Evrope). Ali, od posledica „negativnog odnosa” EU prema NR Kini neće biti pošteđene ni države kandidati za članstvo, uključujući države sa prostora Balkana. I to na dva načina. Jedan je već viđen u slučaju kupovine srpske železare od strane kineske kompanije Hestil. Iako zemlje

$49 \quad$ Security in the Western Balcans, Draft report, Nato Parliamentary Assembly Political committee, Reynell Andreychuc (Canada), Rapporteur, Sub-Sommittee on NATO Partnerships, 28 March 2018, pp. 5-6; www.nato-pa int.

50 Dr Vladimir Krulj, Srbija između privlačnosti EU i ambicija Kine, Financial Times; Preneto: Politika, 5. novembar 2017, str. 4, spoljna@politika.rs

$51 \quad$ Isto, str. 4. 
kandidati za članstvo u EU nemaju punu obaveznost primene propisa EU, delovanje Evropske komisije pokazuje nameru EU da i kod država kandidata „vodi računa” o usaglašenosti ugovora potpisanih sa kineskom stranom sa "pravnim propisima EU”. Drugi način na koji mogu biti osporeni, ugroženi ili zaustavljeni projekti sa NR Kinom u balkanskim državama odnosi se na infrastrukturne i druge projekte koji imaju regionalni karakter i obuhvataju više zemalja, država članica EU i kandidata za članstvo. Zahtevom za proverom o usaglašenosti propisa države članice sa propisima EU (i zaustavljanjem početka realizacije projekta do dobijanja pozitivne ocene od strane Evropske komisije) može biti direktno pogođena i druga(e) država(e) koja(e) učestvuje u projektu. Primer za to je realizacija projekta izgradnje i rekonstrukcije brze železničke pruge Beograd - Budimpešta.

Zahtev Evropske komisije prema Mađarskoj, sa ciljem da se utvrdi da li je projekat izgradnje te pruge „u skladu sa pravilima EU o konkurentnosti" ${ }^{2}$, može u potpunosti zaustaviti izgradnju pruge (ukoliko zaključak Komisije bude negativan po Mađarsku) i u Srbiji, jer je izgradnja dela pruge i to samo kroz Srbiju besmislena. Naravno, Mađarska može doneti odluku i započeti izgradnju pruge i bez saglasnosti Evropske unije, ali bi takav način rešavanja ovog pitanja značio i kraj postojeće strukture i odnosa u Evropskoj uniji. Ideja produženja pruge Budimpešta - Beograd do Pireja (Grčka) podrazumeva uključenje još jedne države članice EU, ali i zemlje kandidata (Makedonije) preko čije teritorije pruga takođe prolazi. Napred pomenuti zahtev Evropske komisije može biti postavljen i prema Grčkoj (kao i drugi zahtevi), i prema Makedoniji, čime se dovodi u pitanje realizacija projekta. Evropska unija ima različite mehanizme na raspolaganju da, ukoliko to želi, oteža ili zaustavi realizaciju različitih projekata unutar Procesa saradnje 16+1, odnosno Inicijative „Pojas i put”. Naravno, mogućnosti delovanja EU su veće među državama članicama, nego među kandidatima za članstvo u EU. To, sa druge strane, još više jača poziciju Srbije, kao zemlje kandidata, da razvija saradnju sa Kinom.

Ali da i zemlje članice EU neće ostati pasivne u odnosu na potrebu jačanja saradnje sa NR Kinom, tj. realizaciju infrastrukturnih projekata, u odnosu na moguće delovanje Evropske unije, pokazuje reakcija Mađarske. Predsednik Vlade Mađarske Viktor Orban je početkom godine na Ekonomskom samitu u Berlinu, uz ocenu da zemljama Centralne Evrope trebaju finansijska sredstva za izgradnju putnih i železničkih pravaca, izjavio „da će se zemlje Centralne Evrope okrenuti Kini, ako im Evropska unija ne obezbedi

52 Pruga Beograd - Budimpešta pod nadzorom EU, https://www.danas.rs, 27. novembar 2017. 
finansijska sredstva za izgradnju potrebne infrastrukture" ${ }^{53}$ Buduće vreme će pokazati svu težinu ove izjave i njenu realnu zasnovanost.

Razmišljanje slično mađarskom sigurno postoji i kod još jednog broja članica EU, ali će njihovo javno reagovanje zavisiti od karaktera odnosa političkih stranaka unutar zemlje, odnosa prema Briselu (EU), i želje da se unapredi saradnja sa NR Kinom.

Ovakvo ponašanje Evropske unije, kroz delatnost Evropske komisije i drugih tela, ukoliko se nastavi, biće glavni faktor usporavanja saradnje sa Kinom unutar Procesa 16+1 i (ne)realizacije brojnih projekata. Naravno, negativni efekti će biti veći među članicama EU, zbog odnosa unutar članica i njihove obaveze „poštovanja propisa EU”, dok će države kandidati biti u povoljnijem položaju jer su u situaciji da samostalno donose brojne odluke i kao zemlje kandidati nisu u „punoj obavezi kad je Evropske unije zakonodavstvo u pitanju".

Kada je reč o drugim velikim državama koje su politički i ekonomski prisutne na prostoru Balkana, kao na primer Turska, njihova saradnja sa balkanskim državama ne dovodi u pitanje „Pojas i put” i realizaciju brojnih projekata. Razlog tome je dvojak. Projekti saradnje balkanskih država sa Kinom, s jedne strane, nisu suprotstavljeni projektima saradnje sa drugim državama, o čemu i same balkanske države vode računa kroz svoje razvojne planove. Sa druge strane, bilateralni odnosi NR Kine sa tim državama, kao na primer sa Turskom, su razvijeni i saradnja sa balkanskim državama i realizacija „Pojasa i puta” ne dovodi u pitanje kvalitet njihovih međusobnih odnosa. Između Turske i Kine neće biti nikakvog sučeljavanja na Balkanu u pogledu odnosa prema Inicijativi „Pojas i put”. Turska je jedna od 64 zemlje koje su od početka uključene u realizaciju „Pojasa i puta”. NR Kina je sa Turskom potpisala i Memorandum o razumevanju na izgradnji „Pojasa i puta". Kina i Turska su postigle važan konsenzus o zajedničkoj saradnji u mnogim oblasti i počele razgovore za realizaciju železničkog projekta brze pruge Istok - Zapad u Turskoj. ${ }^{54}$

Ni odnosi između samih balkanskih državama, koji su često turbulentni, opterećeni dešavanjima iz prošlosti i različitim gledanjima u odnosu na aktuelne teme ${ }^{55}$ (pitanje međusobnih granica ili odnos prema samoproglašenoj nezavisnosti tzv. države Kosovo i dr.) neće dovesti u pitanje realizaciju „Pojasa i puta” i njihove odnose sa NR Kinom. Sve balkanske države su zainteresovane za saradnju sa Kinom, izgradnju infrastrukture, realizaciju

53 Orban. Ako nemamo finansijsku podršku EU, okrećemo se Kini, Politika, 11. januar 2018, str. 4, spoljna@politika.rs

54 Building the Belt and Road..., Ibidem, p. 15.

55 Žarko Obradović. „Pojas i put” - Balkanska perspektiva (političko-bezbednosni aspekti), nav. delo, str. 86-88. 
energetskih projekata, otvaranje fabrika i druge oblike saradnje. Za balkanske države saradnja sa Kinom predstavlja dodatni element unapređenja ekonomskog razvoja i kvaliteta života građana. Koliki će biti obim saradnje tih država zavisi pre svega od političke volje vladajućih političkih snaga u državama Balkana, dok u slučaju država koje su članice EU treba svakako računati i na reakciju Brisela i moguću (ne)saglasnost za saradnju sa Kinom.

Pozicija Srbije za saradnju sa Kinom je u odnosu na sve balkanske države daleko najpovoljnija. Srbija je uspostavila najviši nivo međudržavnih odnosa koje jedna država ima sa NR Kinom a to je "nivo sveobuhvatnosti strateškog partnerstva". Međusobne posete najviših predstavnika dveju država (predsednici državâ, Vladâ i parlamenata) su poslednjih pet godina veoma česte i brojne. Među balkanskim državama Srbija ima najveći broj zaključenih međudržavnih ugovora sa NR Kinom i najveći broj započetih i završenih projekata. Srbija nije još uvek članica Evropske unije već država kandidat, što joj daje veću mogućnost u razvoju odnosa sa Kinom (u odnosu na države članice EU) i odabiru za razvoj zemlje potrebnih projekata. Dve države su potpisale i dokument kojim se garantuje usaglašenost planova razvoja Srbije sa sadržajem „Pojasa i puta”. Dobri međudržavni odnosi Kine i Srbije, oslonjeni na tradiciju prošlosti ali još više na zajedničkom radu u sadašnjosti, uzajamnoj podršci i pomoći u međunarodnim odnosima, realizaciji brojnih projekata, saradnji i povezivanju u obrazovanju, kulturi, nauci i dr. predstavljaju garant buduće saradnje i ujedno primer trećim zemljama da zajednički interesi i želja dve države, uprkos brojnim razlikama, jesu osnovni uslov saradnje i razvoja odnosa između Republike Srbije i Narodne Republike Kine.

\section{LITERATURA}

1. Bendini Roberto - Barone Barbara. "Trade and Economic relations with China 2015", European Parliament, Directorate - General for external policies, Policy Department, 2015.

2. Blagoje S. Babić. Odnosi Kine i Evropske unije: geoekonomska osovina u razvoju, Međunarodna politika, broj 3, 2010.

3. Building the Belt and Road: Concept, Practice and China's Contribution, Office of the heading Group for the Belt and road initiative, May 2017, Foreign Languages Press Co. Ltd, Beijing, China, 2017.

4. The Budapest Guidelines for Cooperation between China and Central and Eastern European Countries, 27/11/2017, www.chine-cier.org. 
5. The Belt and Road: Win-Win Cooperation, Beijing Language and Culture University Press, Handbook.

6. Dr Vladimir Krulj. Srbija između privlačnosti EU i ambicija Kine, Financial Times; Preneto: Politika, 5. novembar 2017, spoljna@politika.rs.

7. Žarko Obradović. Strateško partnerstvo „male” Srbije i „velike” Kine: unutrašnji i međunarodni aspekti saradnje, Institut za političke studije, Srpska politička misao, br. 3/2016, Beograd 2016.

8. Žarko Obradović. „Pojas i put” - Balkanska perspektiva (političko-bezbednosni aspekti), Zbornik radova Novi put svile: Balkanska perspektiva (političko-bezbednosni aspekti) /priredio V. Cvetković; uredništvo Šao Binhong...../Beograd, Fakultet bezbednosti, 2017 (Čigoja štampa).

9. Aleksandar Janković. Privredni razvoj Kine: povezivanje na kineski način, Centar za istraživanje povezivanja Puta svile - CIPO, Beograd 2017.

10. Li Mančang. Tradicionalno prijateljstvo otvara novo poglavlje, saradnjom i zajedničkim naporima težimo prosperitetu, Priče o Kini, Politika 2. mart 2018 god.

11. Dr Liu Zuokui. „Saradnja 16+1” u kontekstu inicijative „Pojas i put”, Zbornik radova Novi put svile: Balkanska perspektiva (političko-bezbednosni aspekti), Fakultet bezbednosti, Čigoja štampa, Beograd 2016.

12. Dr Long Jing. Budućnost saradnje između Kine i Balkana i njene mogućnosti u okviru „Saradnje 16+1” i Inicijative „Pojas i put”, Zbornik radova Novi put svile: Balkanska perspektiva (političko-bezbednosni aspekti), Fakultet bezbednosti, Čigoja štampa, Beograd 2016.

13. Security in the Western Balcans, Draft report, Nato Parliamentary Assembly Political committee, Reynell Andreychuc (Canada), Rapoorteru, SubSommittee on NATO Partnerships, 28 march 2018; www.nato-pa int

14. XI JINPING, The Governance of China, Foregn Ianguages Press, Beijing 2014.

15. Wang Yiwei. The Belt and Road Initiative - What will China offer the world in its rise, NewWorld, Press, Beijing, 2016. 